\title{
KAJIAN STABILITAS COUNTERFORT WALL PADA ESCAPE HILL TERHADAP FREEBOARD DAN RUN UP LEVEL
}

\author{
Tasia Oktanuansania帛, Munirwansyah ${ }^{2)}$, Halida Yunita ${ }^{3)}$ \\ ${ }^{1)}$ Magister Teknik Sipil,Fakultas Teknik, Universitas Syiah Kuala, Banda Aceh \\ 2), 3) Jurusan Teknik Sipil, Fakultas Teknik, Universitas Syiah Kuala, Banda Aceh \\ email: tasya_civil@yahoo.co.id ${ }^{1)}$
}

DOI: http://dx.doi.org/10.29103/tj.v9i1.183

\begin{abstract}
Abstrak
Kota Banda Aceh termasuk salah satu daerah yang terkena bencana tsunami pada 26 Desember 2004 dengan kekuatan gempa 9,3 SR. Mengingat berbagai ancaman gempa yang menimbulkan tsunami dan masih kurangnya upaya yang optimal dalam pembangunan tempat evakuasi maka perlu dilakukan kajian-kajian terhadap tempat evakuasi sementara yaitu bukit buatan (escape hill). Salah satu cara penanggulangan konstruksi bangunan terhadap pengaruh freeboard dan run up level adalah penggunaan dinding tegak pada salah satu model tempat evakuasi tsunami. Tujuan dari penelitian ini adalah mengetahui nilai stabilitas dinding tegak pada escape hill dan faktor keamanan dari dinding tegak. Lokasi penelitian dilakukan di Desa Tibang, Kecamatan Syiah Kuala diperoleh tinggi run up maksimum pada saat tsunami 2004 mencapai 3,70 m. Data yang diperoleh dari lapangan kemudian dibawa ke laboratorium dan dianalisis dengan menggunakan program Plaxis. Kajian dinding penahan tanah pada tempat evakuasi sementara ini menggunakan dinding penahan tipe counterfort wall, stabilitas dinding diperoleh pada ketinggian $8 \mathrm{~m}$. Dari pemodelan yang telah dilakukan, menunjukkan bahwa pemodelan material site dengan variasi nilai kohesi tanah c sebesar - 25\% dan sudut geser dalam tanah $\varphi$ sebesar $+5 \%$ dengan faktor keamanan 2,614 > 1, menghasilkan faktor keamanan yang paling tinggi dibandingkan dengan variasi yang lain. Nilai-nilai parameter tanah (material site) dengan variasi c - 25\% sebesar $0,032 \mathrm{kN} / \mathrm{m}^{2}$ dan $\varphi+5 \%$ sebesar $32,469^{\circ}$ dapat diusulkan untuk menetapkan TOR (Term Of Reference) dan RKS (Rencana Kerja dan Syarat-syarat) dalam pelaksanaan pembangunan escape hill ini.
\end{abstract}

Kata Kunci: Escape Hill, Freeboard, Run up level, Dinding Tegak, Faktor Keamanan

\begin{abstract}
Banda Aceh city was including the tsunami affected area on December 26, 2004 with the strength of the 9.3 SR earthquake. Given the various earthquake threats that had caused tsunami and the lack of optimal efforts in the construction of evacuation sites, it is necessary to conduct studies on temporary evacuation sites, namely escape hill. One method of overcoming building construction on the effect of freeboard and run up level is the use of vertical walls in one of the tsunami evacuation place model that need to be analyzed for maximum height that is firm against the lateral force of the tsunami wave collision. The purpose of this study is to calculate the stability of the vertical wall on the escape hill and calculate the safety factor of the upright wall. This research was conducted in Tibang Village, Syiah Kuala Sub-district, the maximum run up height obtained at the time of the 2004 tsunami was about $3.70 \mathrm{~m}$. The data obtained from the field are then taken to the laboratory and calculated using the Plaxis program. This study of retaining wall at the temporary evacuation site used counterfort wall type, stability obtained at an altitude of $8 \mathrm{~m}$. From the modeling that has been done, it is shown that the modeling of site materials with variations of soil
\end{abstract}

Kajian Stabilitas Counterfort Wall Pada Escape Hill Terhadap Freeboard dan Run Up Level - Tasia Oktanuansania, Munirwansyah, Halida Yunita 
cohesion value $\mathrm{c}$ as $-25 \%$ and the value of the shear angle in the soil $\varphi$ as $+5 \%$ with a safety factor of 2,614 produces the highest safety factor compared to variations compared to other variations. The values of material site parameters with variations $\mathrm{c}$ as $0.032 \mathrm{kN} / \mathrm{m} 2$ and $\varphi$ as $32.469^{\circ}$ could be proposed to determine the Term of Reference (TOR) and work plan and requirement in implementing this escape hill construction.

Keywords: Escape Hill, Freeboard, Run up Level, Vertical Walls, Safety Factor

\section{Latar Belakang}

Indonesia sebagai negara kepulauan secara geografis rentan terhadap bencana alam tsunami. Gempa-gempa yang sebagian besar berpusat di dasar Samudera Hindia dan beberapa di antaranya menimbulkan gelombang laut besar (tsunami). Provinsi Aceh salah satunya kota Banda Aceh termasuk daerah yang terkena bencana tsunami pada 26 Desember 2004 dengan kekuatan gempa 9,3 SR. Mengingat berbagai ancaman gempa yang menimbulkan tsunami dan masih kurangnya upaya yang optimal dalam pembangunan tempat evakuasi maka perlu dilakukan kajian-kajian terhadap tempat evakuasi sementara yaitu bukit buatan (escape hill).

Salah satu cara penanggulangan konstruksi bangunan terhadap pengaruh ketinggian maksimum gelombang yang datang (freeboard) dan ketika rayapan gelombang menghantam suatu struktur merayap ke atas permukaan escape hill (run up level) adalah penggunaan dinding tegak. Dinding tegak atau dinding penahan tanah berfungsi untuk menahan besarnya tekanan tanah akibat gaya lateral tanah.

\section{Metode Penelitian}

\subsection{Lokasi Penelitian}

Berdasarkan peninjauan dan data tsunami yang diperoleh, lokasi tinjauan dilakukan di Desa Tibang, Kecamatan Syiah Kuala diperoleh tinggi run up maksimum pada saat tsunami 2004 mencapai 3,70 m. Escape hill yang dibangun harus mewakili untuk jarak capaian penduduk setempat untuk mengevakuasi diri dalam radius atau jarak yang cukup seperti yang diperlihatkan dalam Gambar 1.

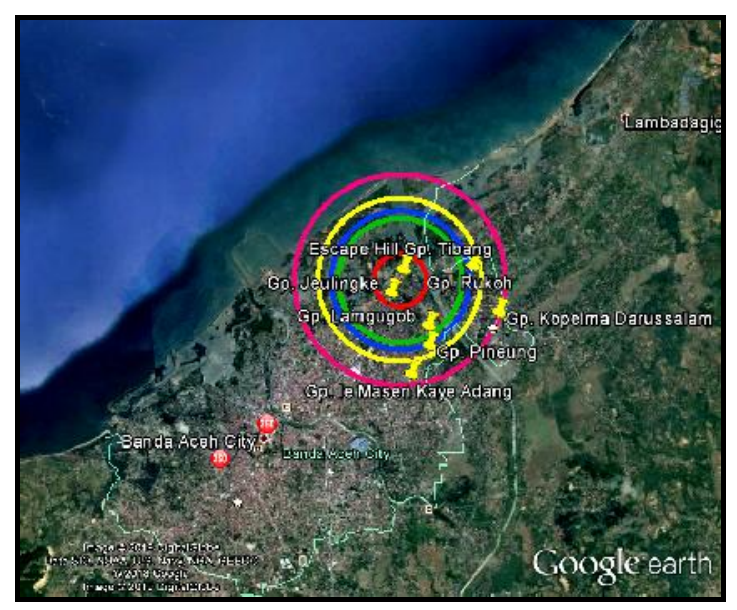

Kajian Stabilitas Counterfort Wall Pada Escape Hill Terhadap Freeboard dan Run Up Level - Tasia Oktanuansania, Munirwansyah, Halida Yunita 
Gambar 1 Radius capaian masyarakat menuju escape hill

Lingkaran warna pada Gambar 1 tersebut adalah desa-desa yang terdekat dan terjauh dari lokasi escape hill, sehingga dapat diketahui masyarakat yang dekat dengan escape hill ketika terjadi tsunami dapat mencapai escape hill, sedangkang untuk yang jauh, dapat dibangun escapel hill di daerah tersebut.

\subsection{Pengumpulan Data}

Proses pengumpulan data pada penelitian ini terbagi atas 2 (dua) yaitu data primer dan data sekunder sebagai berikut:

1. Data primer

Data profil tanah dan karakteristik tanah diperoleh dari pengambilan sampel di lokasi penelitian yang akan diuji di laboratorium Mekanika Tanah, Teknik Sipil Universitas Syiah Kuala.

- Pengambilan Sampel

Pengambilan sampel berasal dari tanah tinjauan di Desa Tibang Kecamatan Syiah Kuala Kota Banda Aceh. Pengambilan sampel tanah untuk penelitian yaitu berupa tes sondir dan pengambilan tanah secara tidak terganggu (undisturbed), selanjutnya dilakukan pengujian terhadap sampel tanah di laboratorium Mekanika Tanah, Teknik Sipil Universitas Syiah Kuala Banda Aceh.

- Pengujian sampel tanah di laboratorium

Pengujian sampel tanah yaitu pengambilan sampel tanah, kemudian dilanjutkan dengan pengujian di labotorium, yaitu pengukuran sifat fisis dan sifat mekanis. Data sifat fisis yang diukur dalam penelitian ini meliputi pengukuran angka pori, kadar air, pengukuran berat jenis, berat volume, batas cair, batas plastis dan analisa butiran. Data sifat mekanis digunakan berupa nilai kohesi dan sudut geser.

2. Data Sekunder

Data yang diperoleh dari peta Tsunami Height Memorial Poles dan gambar Tugu Peringatan Ketinggian Tsunami.

\subsection{Pengolahan Data}

Data yang telah diperoleh dikompilasi secara terstruktur, kemudian dilakukan tahapan pengolahan data sesuai dengan prosedur dengan langkahlangkah sebagai berikut:

1. Data paramater tanah meliputi:

- berat volume tanah $(\gamma)$,

- sudut geser dalam tanah $(\varphi)$,

- kohesi tanah (c),

- modulus young $\left(\mathrm{E}_{\mathrm{ref}}\right)$,

- permeabilitas $(\mathrm{k})$ dan

- poission rasio (v) pada masing-masing lapisan dari profil yang diperoleh.

2. Menganalisis stabilitas lereng dengan cara trial dan error dengan menggunakan program plaxis dimana membutuhkan pemodelan parameter tanah seperti diperlihatkan pada Tabel 1. Nilai pemodelan parameter tanah ini diperoleh dari tanah timbunan yang divariasikan nilai kohesi tanah dan sudut 
geser dalam. Pemodelan ini dilakukan guna memperoleh kondisi yang lebih aman.

\begin{tabular}{ccc}
\multicolumn{4}{c}{ Tabel 1 Pemodelan parameter tanah } \\
\hline $\begin{array}{c}\text { Pemodelan Nilai } \\
\text { Kohesi Tanah } \\
(\mathrm{c}) \text { varian }\end{array}$ & $\begin{array}{c}\text { Pemodelan Nilai Sudut } \\
\text { Geser dalam Tanah } \\
(\varphi) \text { varian }\end{array}$ & $\begin{array}{c}\text { Faktor Keamanan } \\
(\mathrm{FK})\end{array}$ \\
\hline $\mathrm{c}$ & $\varphi$ & FK \\
\hline $\mathrm{c}+25 \%$ & $\varphi-5 \%$ & $\mathrm{FK}$ \\
\hline $\mathrm{c}+50 \%$ & $\varphi-10 \%$ & $\mathrm{FK}$ \\
\hline $\mathrm{c}+75 \%$ & $\varphi-15 \%$ & $\mathrm{FK}$ \\
\hline $\mathrm{c}-25 \%$ & $\varphi+5 \%$ & $\mathrm{FK}$ \\
\hline $\mathrm{c}-50 \%$ & $\varphi+10 \%$ & $\mathrm{FK}$ \\
\hline
\end{tabular}

3. Data yang diperoleh dianalisis dengan menggunakan program Plaxis. Analisis program plaxis memiliki tiga tahapan yaitu tahapan masukan data, tahapan kalkulasi, dan tahapan keluaran data.

a. Tahap masukkan data (input)

Adapun tahapan masukan data, sebagai berikut:

- Memasukkan data tanah dasar;

- Memasukkan data tanah timbunan;

- Menginput perkuatan dinding penahan tanah;

- Memasukkan kondisi muka air tanah

Tabel 2 Nilai parameter tanah pada perencanaan escape hill

\begin{tabular}{|c|c|c|c|c|c|c|c|}
\hline \multirow{14}{*}{ Normal } & \multirow{4}{*}{ Parameter } & \multirow{4}{*}{ Nama } & \multicolumn{3}{|c|}{ Tanah Dasar } & \multirow{2}{*}{$\begin{array}{l}\text { Tanah } \\
\text { Timbunan } \\
\text { Pasir }\end{array}$} & \multirow{4}{*}{ Unit } \\
\hline & & & Pasir & Pasir & Pasir & & \\
\hline & & & Berlanau & Berlanau & Berlanau & & \\
\hline & & & $1 \mathrm{~m}$ & $2 \mathrm{~m}$ & $3 \mathrm{~m}$ & $>3 \mathrm{~m}$ & \\
\hline & Type of behavior & Type & Undrained & Undrained & Undrained & Drained & \\
\hline & Dry soil weigt & $\gamma$ dry & 8,90 & 10,10 & 10,40 & 16,10 & $\mathrm{kN} / \mathrm{m}_{3}$ \\
\hline & Wet soil wet & $\gamma$ wet & 22,84 & 22,76 & 22,96 & 19,24 & $\mathrm{kN} / \mathrm{m}_{3}$ \\
\hline & $\begin{array}{l}\text { Horizontal } \\
\text { permeability }\end{array}$ & $\mathrm{kx}$ & $8,64 \mathrm{E}-03$ & $8,64 \mathrm{E}-03$ & $8,64 \mathrm{E}-03$ & $4,53 \mathrm{E}-03$ & $\mathrm{~m} /$ day \\
\hline & $\begin{array}{l}\text { Vertical } \\
\text { permeability }\end{array}$ & ky & $8,64 \mathrm{E}-03$ & $8,64 \mathrm{E}-03$ & $8,64 \mathrm{E}-03$ & $4,53 \mathrm{E}-03$ & $\mathrm{~m} /$ day \\
\hline & Young's modulus & E ref & 15000 & 10000 & 8000 & 10000 & $\mathrm{kN} / \mathrm{m}_{2}$ \\
\hline & Poisson's Ratio & $v$ & 0,33 & 0,33 & 0,33 & 0,30 & - \\
\hline & Cohession & $\mathrm{C}$ ref & 8,60 & 12,90 & 10,70 & 0,043 & $\mathrm{kN} / \mathrm{m}_{2}$ \\
\hline & Friction angle & $\varphi$ & 31,60 & 29,00 & 32,30 & 30,923 & o \\
\hline & Dilatancy angle & & 0 & 0 & 0 & 0 & - \\
\hline
\end{tabular}

b. Tahap kalkulasi data (calculation)

Analisis perhitungan pada program Plaxis dilakukan dengan tahap kalkulasi data, antara lain :

- Kondisi awal merupakan kondisi perhitungan pada saat beban belum bekerja. Pada kondisi ini dihitung adalah akibat beban berat sendiri;

- Jenis kalkulasi yang digunakan adalah tahapan konstruksi (stage construction);

Kajian Stabilitas Counterfort Wall Pada Escape Hill Terhadap Freeboard dan Run Up Level - Tasia Oktanuansania, Munirwansyah, Halida Yunita 
- Perhitungan deformasi dan perpindahan total, dari perhitungan ini diperoleh gambaran deformasi dan perpindahan total;

- Analisis faktor keamanan terdapat pada prosedur manual control load advanced number of step dengan pilihan phi-c reduction yang tersedia pada perhitungan kondisi plastis.

- Tahap perkuatan, fase dimana tegangan dan regangan akibat berat tanah sendiri, akibat beban luar dan akibat beban perkuatan dinding penahan tanah;

- Proses kalkulasi angka keamanan (FK).

c. Tahap keluaran data (output)

Tahap keluaran data adalah tahap hasil yang diperoleh dari tahap kalkulasi dengan program Plaxis. Hasil yang diperoleh pada tahap keluaran data adalah:

- Faktor kemanan kondisi dengan perkuatan dinding penahan tanah;

- Deformasi yang ditunjukkan dari total displacement.

4. Design untuk jenis dinding penahan tanah yang digunakan Counterfort Wall. Seperti yang diperlihatkan dalam Gambar 2.

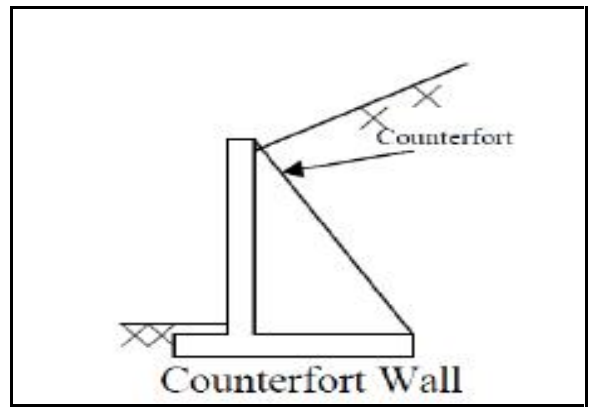

Gambar 2 Struktur penahan tanah

\section{Hasil dan Pembahasan}

\subsection{Hasil Analisis Stabilitas Lereng dengan Dinding Penahan}

Hasil analisis stabilitas lereng dengan meninjau kondisi perkuatan menggunakan dinding penahan tanah counterfort wall dianalisis menggunakan program plaxis, sudut lereng yang digunakan adalah sudut yang diizinkan yaitu $15^{\circ}$. Sudut tersebut dari hasil analisis di mana dalam merencanakan kemiringan lereng, sudut tersebut tidak boleh lebih besar dari $25^{\circ}$ dan tidak boleh kurang dari $10^{\circ}$. Berikut diperlihatkan hasil variasi pemodelan parameter tanah pada Tabel 3 .

Tabel 3 Pemodelan parameter tanah

\begin{tabular}{ccc}
\hline $\begin{array}{c}\text { Pemodelan Nilai } \\
\text { Kohesi Tanah } \\
(\mathrm{c}) \text { varian }\end{array}$ & $\begin{array}{c}\text { Pemodelan Nilai Sudut } \\
\text { Geser dalam Tanah } \\
(\varphi) \text { varian }\end{array}$ & $\begin{array}{c}\text { Faktor Keamanan } \\
(\mathrm{FK})\end{array}$ \\
\hline $\mathrm{c}$ & $\varphi$ & 2,351 \\
\hline $\mathrm{c}+25 \%$ & $\varphi-5 \%$ & 2,484 \\
\hline $\mathrm{c}+50 \%$ & $\varphi-10 \%$ & 2,207 \\
\hline
\end{tabular}




\begin{tabular}{ccc}
\hline$c+75 \%$ & $\varphi-15 \%$ & 2,075 \\
\hline$c-25 \%$ & $\varphi+5 \%$ & 2,614 \\
\hline$c-50 \%$ & $\varphi+10 \%$ & 2,517 \\
\hline
\end{tabular}

Pada Gambar 3 menunjukkan hasil dari variasi pemodelan parameter tanah semakin kecil nilai kohesi dan semakin besar nilai sudut geser maka nilai faktor keamanan semakin naik dibandingkan dengan nilai kohesi tinggi dan nilai sudut geser kecil. Berdasarkan hasil tersebut diambil angka faktor keamanan yang paling besar.

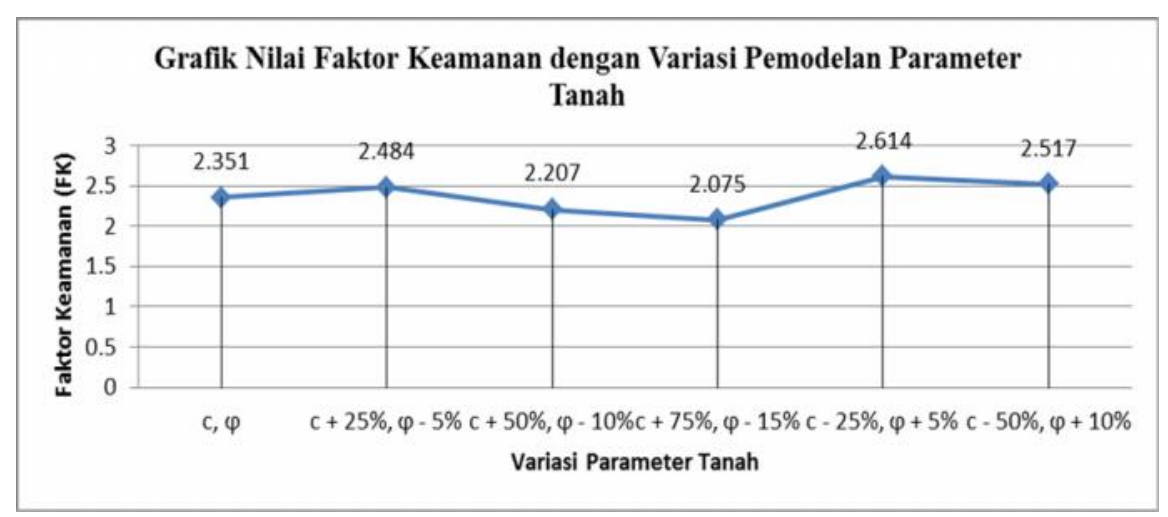

Gambar 3 Grafik nilai faktor keamanan dengan variasi pemodelan parameter tanah

Dari pemodelan yang telah dilakukan, kondisi paling stabil Karena memiliki angka factor keamanan yang paling tinggi dibandingkan yang lain didapat pada pemodelan $\mathrm{c}-25 \%$ dan $\varphi+5 \%$. Hasil perhitungan dari pemodelan dengan tinggi timbunan 12 meter diperlihatkan seperti dalam Gambar 4 sampai dan Gambar 5.

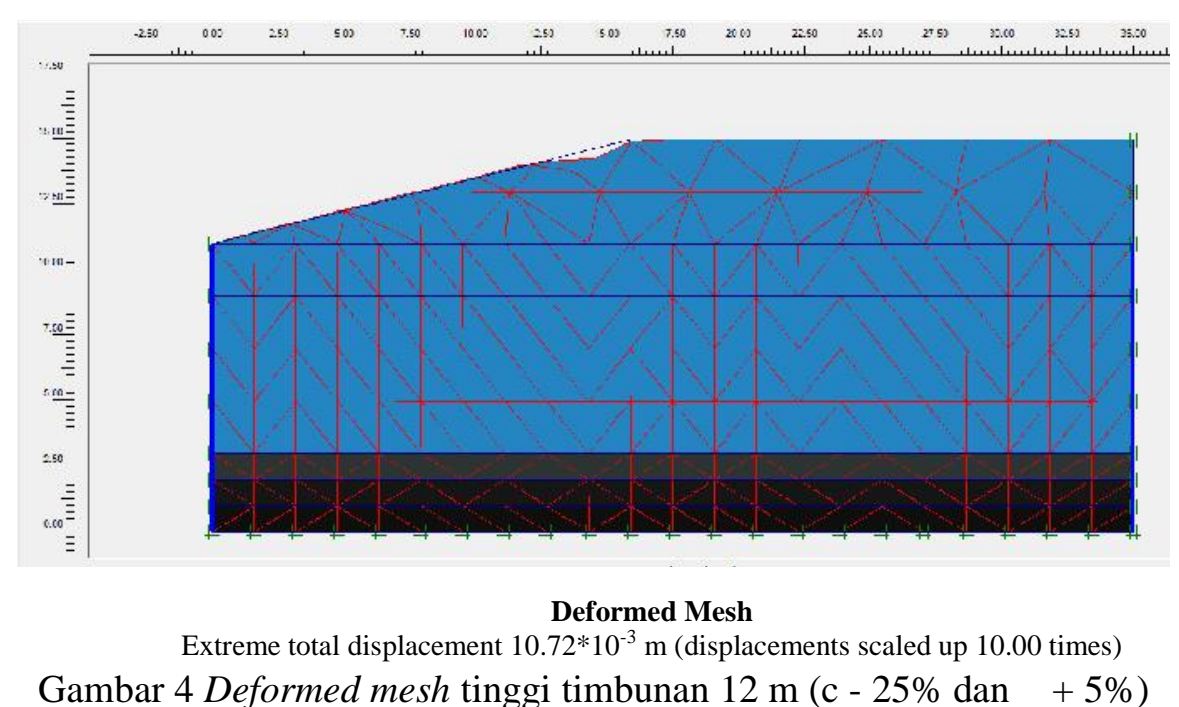

Dari Gambar 4 dilakukan perhitungan pada program plaxis dengan variasi pemodelan dengan menurunkan nilai kohesi (c) dan menaikkan nilai sudut geser 
$(\varphi)$ untuk mendapatkan kondisi yang lebih aman dari kondisi natural. Dari pemodelan yang telah dilakukan, kondisi paling stabil didapat pada pemodelan c $25 \%$ dan $\varphi+5 \%$. Hasil perhitungan dari pemodelan dengan tinggi timbunan 12 meter.

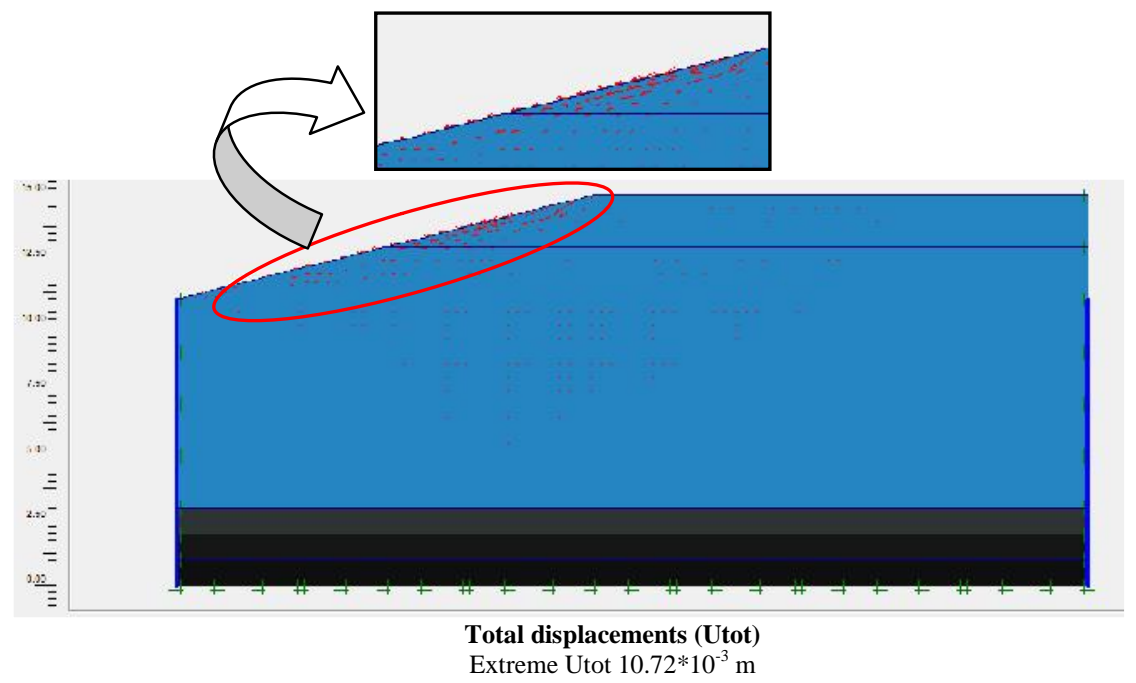

Gambar 5 Total displacement $\left(\mathrm{U}_{\mathrm{tot}}\right)$ arrow tinggi timbunan $12 \mathrm{~m}(\mathrm{c}-25 \%$ dan $\varphi+$ $5 \%)$

Demikian pada Gambar 5 untuk permodelan dengan tinggi timbunan $12 \mathrm{~m}$ diperoleh total Displacement $\left(\mathrm{U}_{\text {tot }}\right)$ arrow mengalami penurunan sebesar 1,072 $\mathrm{cm}$. dapat mengurangi nilai penurunan yang terjadi pada timbunan dan angka keamanan (FK) lereng semakin bertambah dari kondisi normal. Berikut diperlihatkan hasil total penurunan dan angka keamanan pada pemodelan parameter tanah c - $25 \%$ dan $\varphi+5 \%$.

Tabel 4 Hasil total penurunan dan angka keamanan pada pemodelan (c-25\% dan $\varphi+5 \%)$

\begin{tabular}{ccc}
\hline $\begin{array}{c}\text { Ketinggian timbunan } \\
(\mathbf{h})\end{array}$ & $\begin{array}{c}\text { Total Penurunan } \\
\left(\mathbf{U}_{\text {tot }}\right)\end{array}$ & $\begin{array}{c}\text { Angka Keamanan } \\
(\text { FK })\end{array}$ \\
\hline $12,0 \mathrm{~m}$ & $1,072 \mathrm{~cm}$ & 2,614 \\
\hline
\end{tabular}

Berdasarkan hasil perhitungan stabilitas lereng dengan menggunakan dinding penahan tanah counterfort wall yang ditampilkan oleh program plaxis yaitu aman, faktor keamanan yang diperoleh pada kondisi ketinggian timbunan 12 m yaitu 2,614 > 1 artinya lereng tersebut sudah memenuhi syarat angka keamanan yang sesuai.

\subsection{Pembahasan}

Pada kajian ini dinding penahan tanah yang digunakan tipe counterfort wall, dinding ini telah banyak digunakan karena memiliki penyangga pada bagian belakang struktur untuk menyimbangkan struktur akibat beban tanah. Dinding 
penahan yang direncanakan memiliki ketinggian $8 \mathrm{~m}$. Model tempat evakuasi sementara tsunami yang direncanakan memiliki ketinggian $12 \mathrm{~m}$.

Hasil analisis stabilitas dinding tegak pada model tempat evakuasi sementara tsunami terhadap freeboard dan run up level yang menggunakan dinding penahan tanah tipe counterfort wall mampu meningkatkan stabilitas lereng, faktor keamanan yang diperoleh pada kondisi ketinggian timbunan $12 \mathrm{~m}$ yaitu sebesar 2,614 , pada pemodelan tanah dengan variasi c $-25 \%$ dan $\varphi+5 \%$. Faktor keamanan yang dihasilkan memiliki nilai yang paling tinggi di antara variasi $\mathrm{c}$ dan $\varphi, c+25 \%$ dan $\varphi-5 \%, c+50 \%$ dan $\varphi-10 \%, c+75 \%$ dan $\varphi-15 \%, c-50 \%$ dan $\varphi+10 \%$ dengan faktor keamanan 2,351, 2,484, 2,207, 2,075, 2,517.

\section{Kesimpulan dan Saran}

\subsection{Kesimpulan}

Dari pemodelan yang telah dilakukan, menujukkan bahwa pemodelan material site dengan variasi c - 25\% dan $\varphi+5 \%$ dengan faktor keamanan 2,614, menghasilkan factor kemanan yang paling tinggi dibandingkan dengan variasi $\mathrm{c}$ dan $\varphi ; c+25 \%$ dan $\varphi-5 \% ; c+50 \%$ dan $\varphi-10 \% ; c+75 \%$ dan $\varphi-15 \% ; c-25 \%$ dan $\varphi+5 \%$; $-25 \%$ dan $\varphi+5 \%$; $-50 \%$ dan $\varphi+10 \%$ dengan faktor keamanan 2,$351 ; 2,484 ; 2,207 ; 2,075 ; 2,517$;

Nilai- nilai parameter tanah (material site) dengan variasi c sebesar 0,032 $\mathrm{kN} / \mathrm{m}^{2}$ dan $\varphi$ sebesar $32,469^{\circ}$ dapat diusulkan untuk menetapkan TOR (Term Of Reference) dan RKS (Rencana Kerja dan Syarat-syarat) dalam pelaksanaan pembangunan escape hill ini.

\subsection{Saran}

Dalam kajian ini untuk menambah perkuatan dinding tegak dengan cara pemasangan site pile guna untuk lebih memperkuat bangunan dinding yang akan dibangun tempat evakuasi sementara tsunami. Menghitung struktur bangunan dinding penahan tanah tipe counterfort wall untuk dapat membangun dinding penahan di tempat evakuasi sementara tsunami.

\section{Daftar Kepustakaan}

Afrianti, N.,2018, Analisis Stabilitas Lereng Dan Tinggi Kritis Dengan Pemodelan Material Set Pada Perencanaan Escape Hill Menggunakan Software Plaxis, Jurusan Teknik Sipil, Fakultas Teknik Universitas Syiah Kuala, Darussalam-Banda Aceh.

Battjes J. A. (1974), Computation of set-up, longshore currents, run up and overtopping due to wind-generated waves, Report 74-2, Committe on Hydraulics, Department of Civil Engineering, Delft University of Technology, Delft, The Netherlands.

Bowles, J. E., 1993, Sifat Fisis Dan Gioteknis Tanah, tejemahan J.K Hainim, Edisi Kedua, Erlangga, Jakarta.

Kajian Stabilitas Counterfort Wall Pada Escape Hill Terhadap Freeboard dan Run Up 
Das, B.M., 1995, Mekanika Tanah, Jilid 1, Penerbit Erlangga, Jakarta

Faisal, 2016, Alternatif Perkuatan Dinding Penahan Tanah Pada Ruas Jalan Cut Mutia Kota Jantho Menggunakan Software Plaxis, Fakultas Teknik Universitas Syiah Kuala, Darussalam-Banda Aceh.

Hardiyatmo, H.C., 2002, Mekanika Tanah I, Edisi Ketiga, Gadjah Mada University Press, Yogyakarta.

Imran, I., 2014, Pedoman Pelaksanaan Konstruksi Bangunan Dan Bukit Tes Tsunami.

Sundary, D., 2005, Studi Kestabilan Lereng Dengan Perkuatan Bored Pile Menggunakan Metode Elemen Hingga, Tesis Magister ITB Bidang Khusus Geoteknik Program Studi Rekaya Sipil, Bandung.

Suryolelono, K. B., 2003, Bencana Alam Tanah Longsor dalam Perspektif Ilmu Geoteknik, viewed 20 Januari 2017, http://pidato.net/1575_ pengukuhanprof-dr-ir-kabul-basah-suryolelono.

Terzaghi, K., 1987, Mekanika Tanah Dalam Praktek Rekayasa, Jilid 1, Penerbit Erlangga, Jakarta. 